\title{
Duas novas espécies de Belostoma Latreille, 1807 (Hemiptera: Heteroptera: Belostomatidae) do grupo plebejum sensu Nieser, 1975
}

\author{
José Ricardo Inacio RIBEIROํ, Viviani Pereira ALECRIM²
}

\section{RESUMO}

Representantes do grupo plebejum são encontrados de Honduras até o sul da América do Sul e compreendem sete espécies de pequeno porte. Como resultado de um estudo de revisão do grupo, são descritas duas espécies novas: Belostoma estevezae Ribeiro \& Alecrim, sp. nov., do Estado do Mato Grosso, Brasil, similar a B. nicaeum Estévez \& Polhemus, 2007, em termos de carena prosternal, e $B$. nessimiani Ribeiro \& Alecrim, sp. nov., do Estado do Amazonas, Brasil, sendo bastante similar a $B$. parvum Estévez \& Polhemus, 2007, em termos de genitália masculina. Uma chave de identificação para as espécies do grupo plebejum com as espécies novas incluídas é fornecida.

PALAVRAS-CHAVE: Nepomorpha, Barata d'água, Taxonomia, Região Neotropical, Brasil.

\section{Two new species of Belostoma Latreille, 1807 (Hemiptera: Heteroptera: Belostomatidae) of plebejum group sensu Nieser, 1975}

\begin{abstract}
Species of plebejum group comprises seven extant small species of giant water bugs. This group is currently reported from Honduras to southern South America. Two new species are described as a result from a revisional study of this group: Belostoma estevezae Ribeiro \& Alecrim, sp. nov., from Mato Grosso State, Brazil, and B. nessimiani Ribeiro \& Alecrim, sp. nov., from Amazonas State, Brazil. The prosternal keel of B. estevezae, sp. nov., is similar to that of B. nicaeum Estévez \& Polhemus, 2007, while the male genitalia structures of B. nessimiani, sp. nov., is similar to those of B. parvum Estévez \& Polhemus, 2007. A key to the species of plebejum group with new species included is also provided.
\end{abstract}

KEYWORDS: Nepomorpha, Giant water bugs, Taxonomy, Neotropics, Brazil.

'Departamento de Zoologia, Instituto de Biologia, Universidade Federal do Rio de Janeiro, Caixa Postal 68044, 21944-970, Rio de Janeiro, RJ, Brasil, E-mail: belostom@acd.ufrj.br ${ }^{2}$ Divisão do Curso de Entomologia, Instituto Nacional de Pesquisas da Amazônia - INPA, Caixa Postal 478, 69083-970, Manaus, AM, Brasil, E-mail: alecrim@inpa.gov.br 


\section{INTRODUÇÃO}

Com base na subdivisão proposta por Lauck \& Menke (1961), a subfamília Belostomatinae Lauck \& Menke, 1961 compreende seis dos oito gêneros descritos de belostomatídeos conhecidos (Lauck \& Menke, 1961; Polhemus, 1995). Belostoma Latreille, 1807, um desses seis gêneros, é representado por um grande número de espécies na América do Sul (Nieser, 1975). Das 74 espécies distribuídas na Região Neotropical, 40 foram registradas no Brasil até o momento (Ribeiro, 2007).

A escassez de material em coleções para muitas espécies tornou o entendimento da taxonomia do gênero difícil (Bachmann, 1977). Das poucas grandes revisōes existentes, algumas antigas (e.g. Mayr, 1871) ou incompletas (Lauck, 1962, 1963, 1964) são os únicos materiais disponíveis para a identificação e o estabelecimento, ainda muito incipiente, da sistemática de suas espécies.

Das revisões conhecidas, mesmo que ainda incompletas, o grupo de trabalhos de Lauck $(1962,1963,1964)$ foi importante, pois as descriçōes das espécies tratadas foram realizadas com base no estudo morfológico do falo. $\mathrm{O}$ uso dessa estrutura na taxonomia do gênero contribui, desde então, para a identificação e descrição mais criteriosas de algumas espécies consideradas como próximas morfologicamente. Os trabalhos desse autor não trataram daquelas espécies cujos representantes eram de pequeno porte, pois nessas, possivelmente, a dificuldade encontrada por ele em estudar e compreender sua taxonomia estaria relacionada ao fato de serem espécies com proximidade morfológica muito grande (Estévez, 1996). Belostoma foi organizado em 16 grupos de espécies em Lauck (1962), a partir de uma avaliação da similaridade morfológica geral entre esses táxons. Os seguintes grupos e suas respectivas espécies não tiveram sua taxonomia detalhada: grupos denticolle Lauck, 1962, oxyurum Lauck, 1962, plebejum Lauck, 1962 e pygmeum Lauck, 1962.

Como recente contribuição, o grupo denticolle foi revisado por Estévez \& Polhemus (2001), sendo adicionada posteriormente a espécie $B$. loprettoa Estévez \& Armúa-deReyes, 2003 por Estévez \& Armúa-de-Reyes (2003).

O grupo plebejum sensu Nieser, 1975, com sete espécies descritas, ocorre da América Central (Honduras) ao sul da América do Sul (Argentina) (Estévez, 1996). Belostoma nicaeum Estévez \& Polhemus, 2007 e B. parvum Estévez \& Polhemus, 2007 foram registradas no norte da América do Sul. Belostoma minusculum (Uhler, 1884) ocorre de Honduras à Venezuela. A espécie B. lariversi De Carlo, 1960 ocorre no Peru, enquanto B. pygmeum (Dufour, 1863) foi registrada no Peru, Bolívia, Paraguai e sul do Brasil (Paraná). Belostoma plebejum (Stål, 1860) e B. micantulum são as espécies com maior área de distribuição na América do Sul, ocorrendo desde a Venezuela até a Argentina (Estévez \& Polhemus, 2007; Mayr, 1871;
Menke \& Lauck, 1962; Nieser \& Melo, 1997; Ribeiro, 2007; Stål, 1860).

Ao ser proposto por Lauck (1962), o grupo plebejum compreendia as espécies $B$. micantulum, $B$. minusculum e $B$. plebejum. Lauck (1962) definiu o grupo plebejum com base na existência de uma protuberância ventro-apical no divertículo ventral do falo, condição essa, entretanto, considerada duvidosa na época. Lauck (1962) não tratou as espécies do grupo de forma mais detalhada, isto é, com descriçōes pormenorizadas em seus trabalhos, embora o tenha incluído em uma chave de identificação para os grupos de espécies propostos por ele.

Com base no espessamento conspícuo das margens látero-dorsais do divertículo ventral, Lauck (1962) definiu o grupo pygmeum, o qual compreendia as espécies $B$. lariversi e $B$. pygmeum. Apesar de ter estabelecido seus integrantes como diferentes dos do grupo plebejum, não tratou essas espécies de forma mais detalhada também, embora tenha incluído esse grupo na mesma chave de identificação para os grupos de espécies propostos por ele. Segundo Nieser (1975), a condição conspícua do divertículo ventral nessas duas espécies representaria um caso extremo de especialização dos representantes das espécies do grupo plebejum, o que o fez considerar as espécies do grupo pygmeum como parte desse grupo. Estévez \& Polhemus (2007) adicionaram posteriormente, em concordância com o estudo de Nieser (1975), as novas espécies B. nicaeum e B. parvum ao grupo. Além disso, os autores comentaram que o aspecto arredondado e pouco proeminente da carena prosternal é uma característica compartilhada por todas as espécies do grupo. No entanto, a característica mais evidente é, provavelmente, a referente à condição do falo, curvado ventralmente (Estévez, 1996; Nieser, 1975), a qual distingue todas as espécies do grupo das demais de Belostoma.

Neste trabalho, como resultado de um estudo de revisão das espécies do grupo plebejum, duas novas espécies do Brasil são descritas, além de notas taxonômicas e uma chave de identificação para as espécies do grupo com as espécies novas incluídas, tendo como base a chave já confeccionada em Estévez \& Polhemus (2007).

\section{MATERIAL E MÉTODOS}

O material estudado foi proveniente das seguintes coleçóes: American Museum of Natural History, New York, Estados Unidos da América (AMNH); Departamento de Zoologia, Instituto de Biologia, Universidade Federal do Rio de Janeiro, Rio de Janeiro, Brasil (DZRJ); Instituto Nacional de Pesquisas da Amazônia, Manaus, Brasil (INPA); Museu Nacional, Universidade Federal do Rio de Janeiro, Rio de Janeiro, Brasil (MNRJ). Todos os acrônimos foram estabelecidos conforme Arnett-Jr. et al. (1993), exceto DZRJ. 
A citação do material examinado foi apresentada em ordem analítica, do Norte para o Sul. Adotaram-se vírgulas para separar as diferentes informações de um mesmo espécime (localidade, data de coleta, coletor e identificador, caso houvesse), informaçôes entre parênteses para indicar os coletores e as instituiçôes que armazenam as respectivas coleçôes de insetos e pontos ou ponto-e-vírgulas (no caso dos espécimes conterem informaçōes iguais) para separar um espécime de outro. Eventualmente, aspas foram usadas para citar termos não muito claros, da mesma forma que se encontram na etiqueta do espécime. Estados são indicados na lista, em itálico. Ainda na listagem, a letra " $m$ " é referente ao sexo masculino e "f" ao sexo feminino.

Para obtenção do comprimento total e da largura máxima dos adultos, utilizou-se um paquímetro manual de acurácia de $0,1 \mathrm{~mm}$. Todas as outras medidas foram tomadas com o auxílio de uma ocular milimetrada de acurácia de 0,01 mm acoplada a um estereoscópio. As medidas tomadas estão indicadas na Figura 1. Foi usado todo o material disponível de cada espécie tratada neste estudo para a obtenção das medidas.
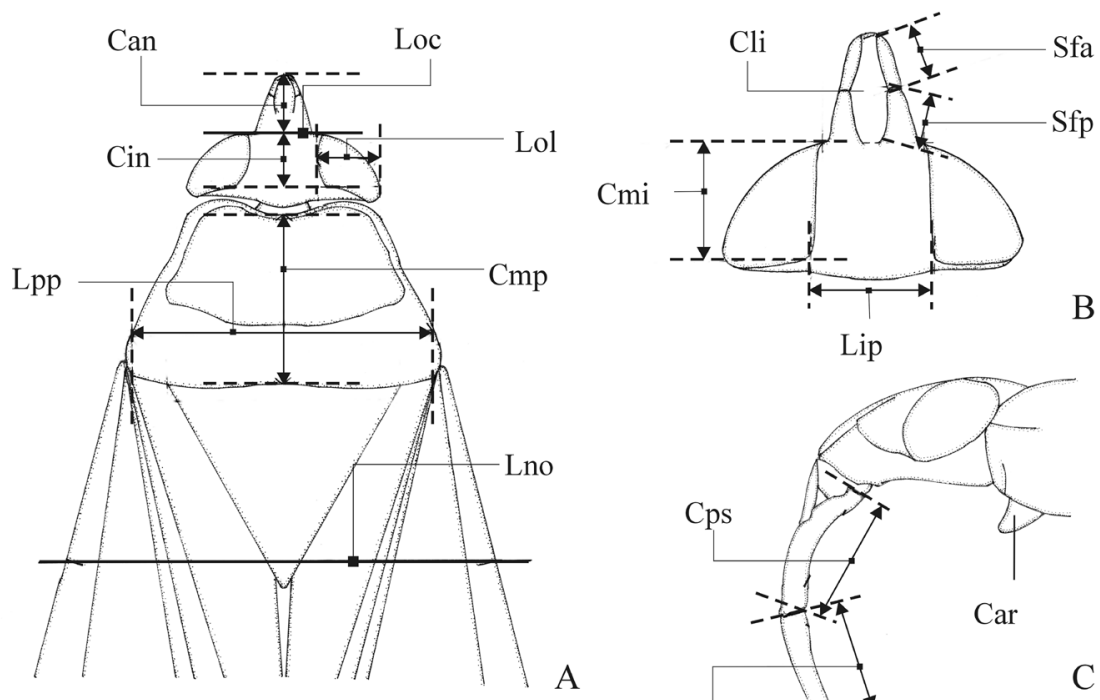

Lip
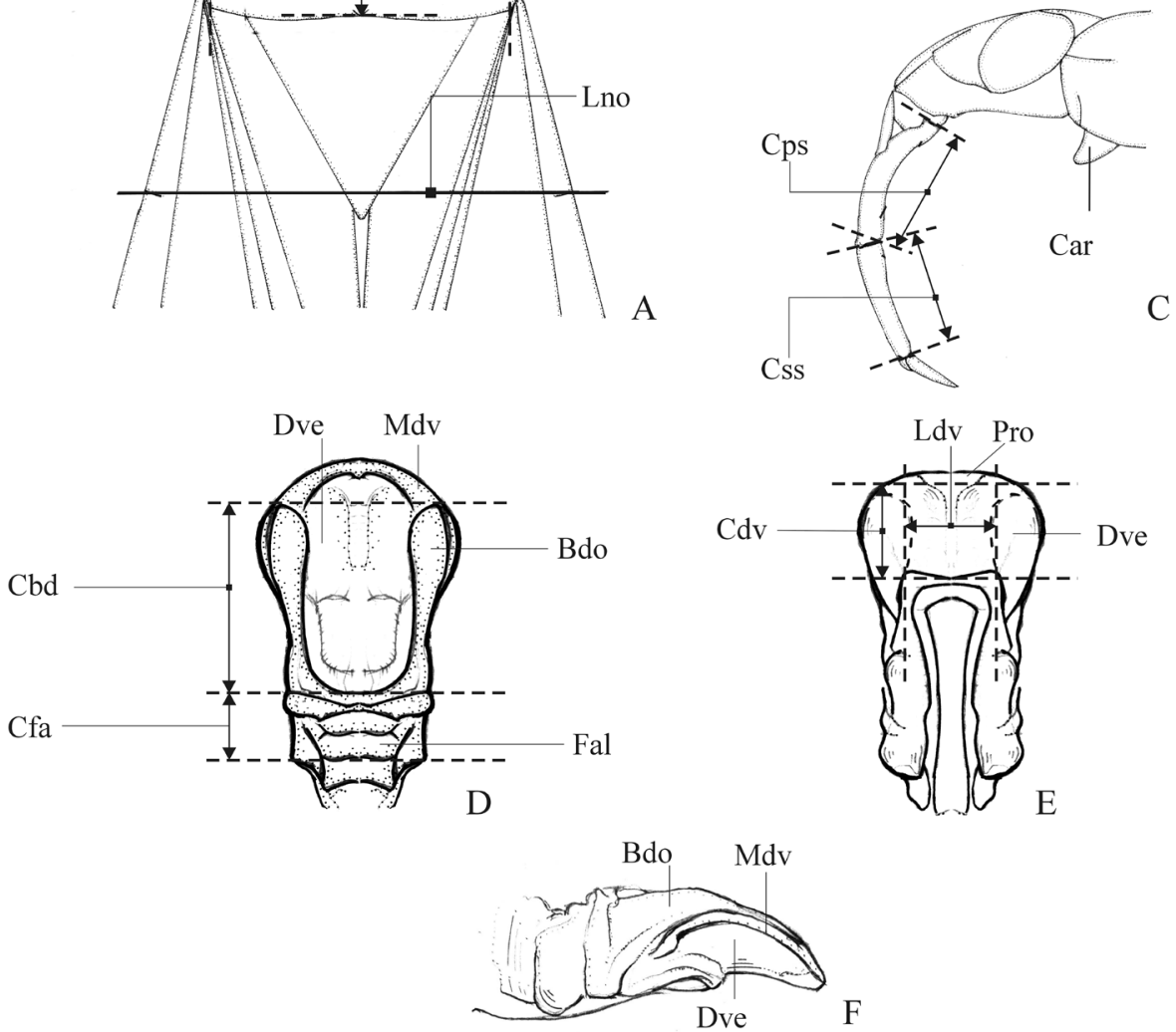

Figura 1 - Estruturas usadas na obtenção de características para a descrição de Belostoma estevezae Ribeiro \& Alecrim, sp. nov. e B. nessimiani Ribeiro \& Alecrim, sp. nov. (Belostomatidae): A, cabeça, pronoto, mesonoto, asas e parte do abdome, vista dorsal; B, cabeça, vista dorsal; C, cabeça e parte do protórax, vista lateral; D-E, falossoma: D, vista dorsal; E, vista ventral; F, vista lateral. Bdo - braços dorsais; Can - comprimento do anteóculo; Car - carena prosternal; Cbd - comprimento dos braços dorsais; Cdv - comprimento do divertículo ventral; Cfa - comprimento do falossoma; Cin - comprimento do interóculo; Cli - clípeo; Cmi - comprimento da margem interna do olho; $\mathrm{Cmp}$ - comprimento do pronoto em sua linha mediana; Cps - comprimento do primeiro segmento do rostro; Css - comprimento do segundo segmento do rostro; Dve - divertículo ventral; Fal - falossoma; Ldv - largura do divertículo ventral; Lip - largura interocular posterior; Lno - linha nodal; Loc - linha ocular; Lol - largura do olho; Lpp - largura posterior do pronoto; Mdv - margem do divertículo ventral; Pro - protuberância ventro-apical; Sfa - porção anterior da sutura frontogenal; Sfp - porção posterior da sutura frontogenal. 
Para confecção de todos os desenhos, foram usados um microscópio óptico da marca ZEISS (AXIOLAB) e um estereoscópio da marca ZEISS (SV-6), ambos com câmara clara. As fotografias usadas neste estudo foram obtidas com de câmara fotográfica modelo MC 80, acoplada a um estereoscópio, ambos da marca ZEISS. O monitoramento das imagens para o computador foi realizado pelo programa AXIOVISION 3.0 SP4 no Laboratório de Captação de Imagens do Instituto de Biologia, Universidade Federal do Rio de Janeiro (UFRJ), Rio de Janeiro, Brasil.

As terminologias dos seguintes autores foram empregadas nas descriçôes das características da cabeça, tórax e abdome: Estévez (1996), Hamilton (1981), Lauck (1962), Nieser (1975), Parsons (1964, 1974) e Ribeiro (2007) para as áreas, escleritos e suturas da cabeça, do tórax e do abdome; Estévez et al. (2006) e Gorb \& Perez-Goodwyn (2003) para o sistema de acoplamento dos hemiélitros ao corpo; Estévez (1996) e Ribeiro (2007) para a genitália masculina.

Para a descrição dos diferentes aspectos da protuberância ou do "botão alar" (wing knob) do sistema de acoplamento dos hemiélitros ao corpo (sistema Druckknopf) (Figura 2, Apc) e do falossoma, os procedimentos descritos em Ribeiro (2005) foram adotados a fim de otimizar a preparação e observação das estruturas.

Após o exame, as partes removidas foram acondicionadas em microtubos com glicerina, devidamente vedados e, em seguida, guardados juntamente aos espécimes-tipo.

\section{RESULTADOS}

Belostoma estevezae Ribeiro \& Alecrim, sp. nov.

(Figuras 3A-I)

Material-tipo. - Holótipo: BRASIL. Mato Grosso Porto Velho, Rio Tapirapé, 18.XII.1962, (B. Malkin), J. R. I. Ribeiro det. 2006: $1 \mathrm{~m}$ (MNRJ [doado pelo AMNH]); parátipos: $1 \mathrm{~m}$ e $1 \mathrm{f}$ (DZRJ [doado pelo $\mathrm{AMNH}$ ]).

\section{Descrição do holótipo (Figura 3I)}

Biometria. Comprimento total do corpo: $11,3 \mathrm{~mm}$; largura máxima do corpo: $5,4 \mathrm{~mm}$; comprimento do primeiro segmento do rostro: $0,60 \mathrm{~mm}$; comprimento do segundo segmento do rostro: 0,64 $\mathrm{mm}$; comprimento do anteóculo: $0,70 \mathrm{~mm}$; comprimento da porção anterior da sutura frontogenal: $0,45 \mathrm{~mm}$; comprimento da porção posterior da sutura frontogenal: $0,45 \mathrm{~mm}$; comprimento do interóculo: $0,80 \mathrm{~mm}$; comprimento do pronoto em sua porção mediana: $1,90 \mathrm{~mm}$; largura posterior do pronoto: $3,80 \mathrm{~mm}$.

Coloração. - Corpo castanho-claro.

Cabeça e tórax. Largura interocular posterior 1,86 vezes o comprimento do anteóculo e 1,86 vezes a largura de um olho. Carena prosternal de aspecto retangular, voltada anteriormente, com sua borda anterior curva; ápice obtuso, sem tubérculos (Figura 3A); porção distal do componente complementar do sistema de acoplamento dos hemiélitros ao corpo, acoplado ao tórax, arredondada (como na Figura 2D).

Genitália masculina (Figuras 3B-H). - Razão entre a largura e o comprimento do divertículo ventral do falossoma igual a 0,88 ; ápice do divertículo ventral (Api) ligeiramente fendido, sem reentrâncias apicais evidentes em vista dorsal; margens látero-dorsais do divertículo ventral (Mdv) não espessadas; depressão mediana e dorsal (Dep) desenvolvida, não atingindo a base dos braços dorsais; braços dorsais (Bdo) ligeiramente convergentes, mais curtos que a base do falossoma; ápice do divertículo ventral, em vista ventral, truncado ou cortado, com uma ligeira depressão na porção mediana; porção ventro-apical mediana do divertículo ventral com protuberância (Pro) desenvolvida; margens láteromedianas do divertículo ventral (Mlm), em vista ventral, curvas e pouco acentuadas.

Biometria dos parátipos ( $\mathrm{m} / \mathrm{f}$ ). Comprimento total do corpo: 11,8 mm / 11,8 mm; largura máxima do corpo: 5,7 $\mathrm{mm} / 5,4 \mathrm{~mm}$; comprimento do primeiro segmento do rostro: $0,56 \mathrm{~mm} / 0,58 \mathrm{~mm}$; comprimento do segundo segmento do rostro: 0,60 mm / 0,62 $\mathrm{mm}$; comprimento do anteóculo: $0,74 \mathrm{~mm} / 0,74 \mathrm{~mm}$; comprimento da porção anterior da sutura frontogenal: $0,42 \mathrm{~mm} / 0,42 \mathrm{~mm}$; comprimento da porção posterior da sutura frontogenal: $0,42 \mathrm{~mm} / 0,42$ $\mathrm{mm}$; comprimento do interóculo: $0,80 \mathrm{~mm} / 0,83 \mathrm{~mm}$; comprimento do pronoto em sua porção mediana: $2,00 \mathrm{~mm}$ / 2,03 mm; largura posterior do pronoto: 4,00 mm / 4,06 $\mathrm{mm}$.

\section{ETIMOLOGIA}

Essa nova espécie foi nomeada em homenagem à Dra Ana Lia Estévez (Museo de La Plata, La Plata, Argentina), cuja dedicação à entomologia e ao estudo dos percevejos aquáticos inspirou-nos e estimulou-nos no estudo dos belostomatídeos.

\section{NOTAS}

Muitas características são compartilhadas entre as espécies do grupo pygmeum e B. estevezae, sp. nov. O formato da carena prosternal da nova espécie (Figura 3A) é muito similar ao das espécies do grupo pygmeum, especialmente da espécie $B$. nicaeum. Essa estrutura apresenta-se, em ambas as espécies, voltada para a parte anterior do corpo e com a borda anterior curva, condição também encontrada nas outras espécies do grupo pygmeum. Entretanto, diferentemente das espécies do grupo pygmeum, as margens do divertículo ventral não são espessadas em B. estevezae, sp. nov. (Figuras 3B, 3E). No que concerne ao tamanho do corpo, as medidas de seu comprimento e de sua largura estão muito próximas daquelas tomadas dos espécimes examinados de $B$. nicaeum 

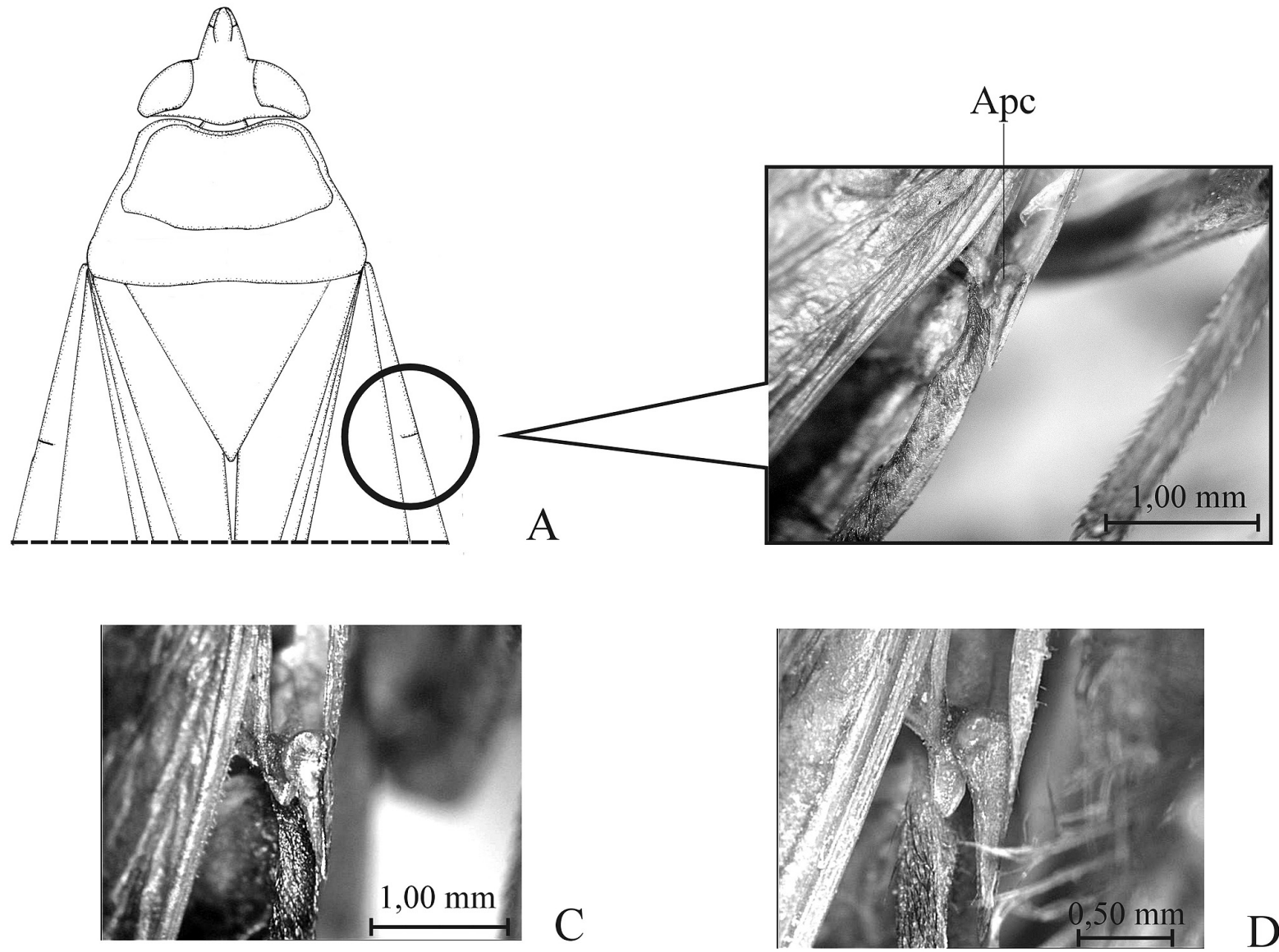

Figura 2 - Sistema de acoplamento anterior do primeiro par de asas ao corpo em Belostoma Latreille (Belostomatidae) (sistema Druckknopf). Detalhamento da estrutura complementar do aparato, situada no tórax: A, localização do aparato complementar no tórax, vista dorsal; B, tórax sem 0 hemiélitro direito: protuberância ou "botão alar" (wing knob) localizada na porção distal do lobo do mesepímero, em uma depressão entre as veias C e Sc do hemiélitro, vista dorsal; C, protuberância piriforme, mais estreita do que comprida; D, protuberância arredondada, quase tão larga quanto comprida. Apc, aparato complementar do sistema de acoplamento Druckknopf.

e B. pygmeum (entre 11,1 e $13,7 \mathrm{~mm}$ de comprimento). No entanto, representantes de $B$. nicaeum apresentam o comprimento do primeiro segmento do rostro bem menor que o comprimento do segundo (Estévez \& Polhemus, 2006).

Belostoma estevezae, sp. nov. enquadra-se no passo 9 da chave de Nieser \& Melo (1997:60), o qual distingue $B$. micantulum de B. plebejum. Essa nova espécie está em melhor conformidade com $B$. micantulum pois ambas se enquadram no intervalo de comprimento do corpo de 10,5 a 13,0 $\mathrm{mm}$. Os representantes de B. micantulum e B. estevezae, sp. nov. (Figuras 3B, 3F-G) apresentam o divertículo ventral mais arredondado, enquanto o dos representantes de $B$. plebejum, mais elíptico, apresenta uma curva ligeiramente mais acentuada em sua porção látero-mediana. Ainda em B. plebejum, a porção ventro-apical do divertículo ventral apresenta uma protuberância ligeiramente mais pronunciada
(Nieser, 1975:127). Quanto às duas espécies mais similares, os representantes de $B$. micantulum apresentam o divertículo ventral com reentrâncias apicais mais conspícuas, em vista dorsal, do que no divertículo ventral dos de $B$. estevezae, sp. nov. (Figuras 3B, D), os braços dorsais mais afastados do seu ápice e a região dorso-mediana do divertículo com depressão longitudinal mais desenvolvida. Belostoma estevezae, sp. nov., entretanto, apresenta o ápice do divertículo ventral com uma fenda mais suave em vista dorsal (Figura 3C, Api).

Belostoma estevezae, sp. nov. enquadra-se no passo $6 \mathrm{da}$ chave de Estévez \& Polhemus (2007), o qual distingue $B$. minusculum de $B$. pygmeum. Essa nova espécie está em melhor conformidade com B. minusculum, pois ambas apresentam as margens látero-dorsais do divertículo ventral não espessadas (Figura 3E) e o comprimento do primeiro segmento do rostro quase igual ao comprimento do segundo. Entretanto, os braços 

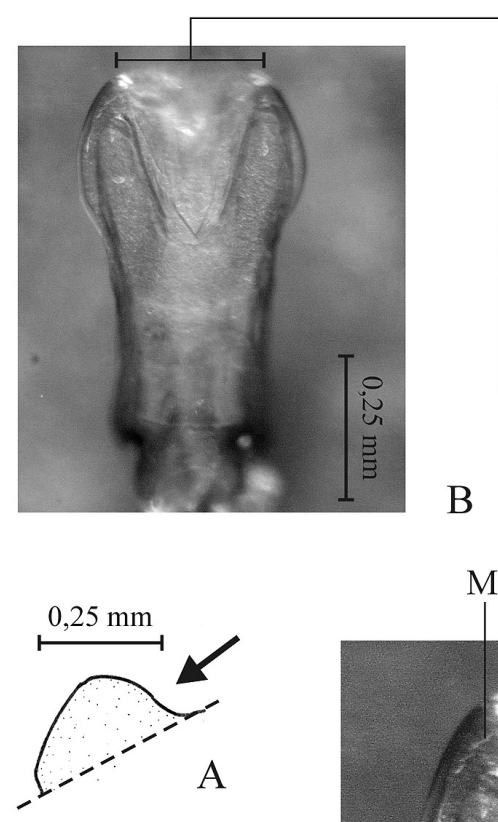

A

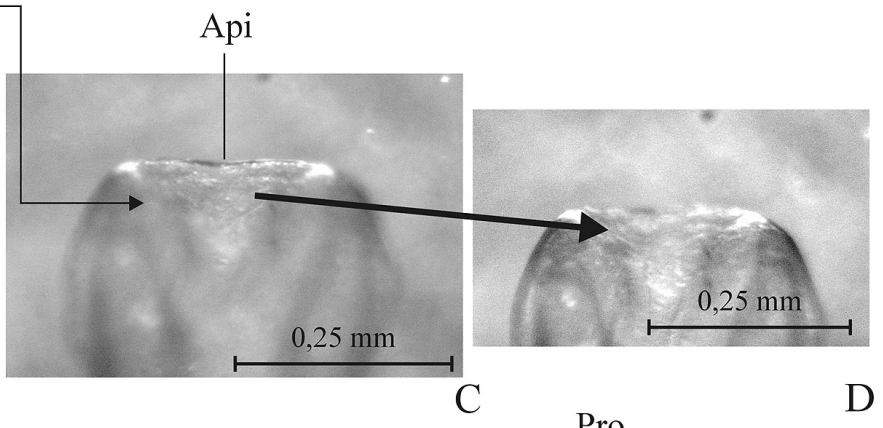

Pro

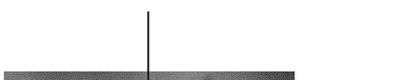

Bdo

岁

$\mathrm{E}$

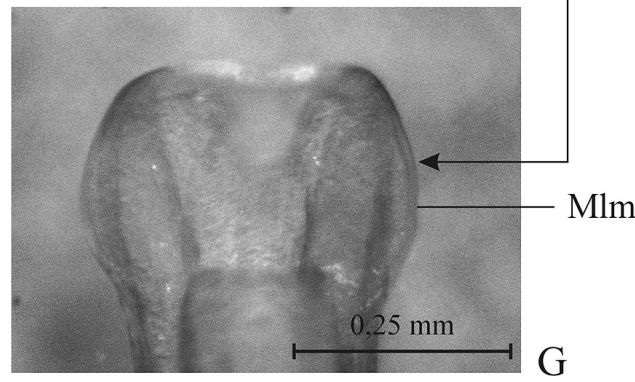

$\stackrel{0,25 \mathrm{~mm}}{\longmapsto} \mathrm{H}$

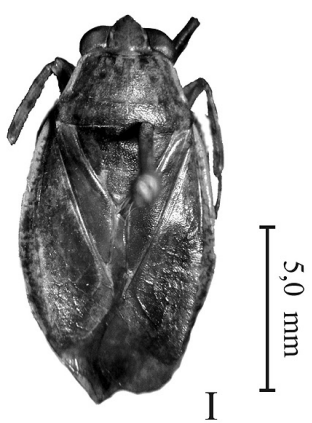

Figura 3 - Belostoma estevezae Ribeiro \& Alecrim, sp. nov. (Belostomatidae). Holótipo (AMNH): A, carena prosternal, vista lateral: seta indicando a ligeira curvatura da porção anterior da carena prosternal; B-G, falossoma: B, vista dorsal; C-D, porção posterior do falossoma, vista dorsal: C, detalhe do ápice do divertículo ventral; $D$, detalhe da depressão mediana próxima ao ápice do divertículo ventral; $E$, detalhe do formato do braço dorsal e da margem látero-mediana do divertículo ventral mostrando seus aspectos, vista dorsal; F, vista ventral; G, porção posterior do falossoma mostrando o formato das margens láteromedianas do divertículo ventral, vista ventral; $\mathrm{H}$, vista lateral; I, holótipo, vista dorsal. Api, ápice do divertículo ventral; Bdo, braços dorsais; Dep, depressão mediana dorsal; Mdv, margem látero-dorsal; Mlm, margem látero-mediana dorsal; Pro, protuberância ventro-apical mediana.

dorsais do divertículo ventral dos espécimes examinados de B. minusculum são mais convergentes e ligeiramente mais estreitos do que os dos representantes de B. estevezae sp. nov., e as margens látero-dorsais do divertículo ventral de $B$. estevezae sp. nov. são mais marcadas do que as da espécie $B$. minusculum (Figuras 3B, 3E).

Belostoma nessimiani Ribeiro \& Alecrim, sp. nov.

(Figuras 4A-I) 
Material-tipo. Holótipo: BRASIL. Amazonas - Rio Amazonas, Paraná da Trindade, Lírio do Vale, Lago do Albano [ponto A18 em armadilha U.V.], [-2,414180 ${ }^{\circ},-57,49993^{\circ}$, 24.IX.2003, (P. de Marco \& N. Ferreira-Jr), J. R. I. Ribeiro \& V. P. Alecrim det. 2006: $1 \mathrm{~m}$ (INPA). Parátipos: BRASIL. Pará - Rio Amazonas: Juriti, Recreio, Paraná [ponto A20 em armadilha U.V.], [-2,06549 $\left.{ }^{\circ},-55,56254^{\circ}\right]$, 26.IX.2003, (P. de Marco \& N. Ferreira-Jr), J. R. I. Ribeiro \& V. P. Alecrim det. 2006: 1 f e 2 m (DZRJ); Almerim, Paranaquara, Paraná ["barco"] [ponto A25 em armadilha U.V., no barco], $\left[-1,74198^{\circ},-53,17167^{\circ}\right], 05 . X .2003,1 \mathrm{~m}$ (INPA). Amazonas - Rio Amazonas, Paraná da Trindade, Lírio do Vale, Lago do Albano [ponto A18 em armadilha U.V.], [-2,414180', -57,49993이, 24.IX.2003, (P. de Marco \& N. Ferreira-Jr), J. R. I. Ribeiro \& V. P. Alecrim det. 2006: $1 \mathrm{~m}$ e $1 \mathrm{f}$ (INPA).

\section{Descrição do holótipo (Figura 4I)}

Biometria. Comprimento total do corpo: $11,8 \mathrm{~mm}$; largura máxima do corpo: $5,8 \mathrm{~mm}$; comprimento do primeiro segmento do rostro: $0,64 \mathrm{~mm}$; comprimento do segundo segmento do rostro: $0,74 \mathrm{~mm}$; comprimento do anteóculo: $0,64 \mathrm{~mm}$; comprimento da porção anterior da sutura frontogenal: $0,32 \mathrm{~mm}$; comprimento da porção posterior da sutura frontogenal: $0,32 \mathrm{~mm}$; comprimento do interóculo: $0,80 \mathrm{~mm}$; comprimento do pronoto em sua porção mediana: $1,90 \mathrm{~mm}$; largura posterior do pronoto: $3,80 \mathrm{~mm}$.

Coloração. - Corpo castanho-escuro.

Cabeça e tórax. - Largura interocular posterior duas vezes o comprimento do anteóculo e 1,73 vezes a largura de um olho. Carena prosternal de aspecto ligeiramente retangular, não voltada anteriormente, com sua borda anterior reta; ápice agudo, sem tubérculos (Figura 4A); porção distal do componente complementar do sistema de acoplamento dos hemiélitros ao corpo, acoplado ao tórax, arredondada.

Genitália masculina (Figuras 4B-H). - Razão entre a largura e o comprimento do divertículo ventral do falossoma igual a 1,00; ápice do divertículo ventral truncado, com reentrâncias apicais pouco evidentes em vista dorsal; margens látero-dorsais do divertículo ventral, não espessadas; depressão mediana e dorsal pouco desenvolvida; braços dorsais abruptamente convergentes, mais curtos que a base do falossoma; ápice do divertículo ventral, em vista ventral, truncado ou cortado; porção ventro-apical mediana do divertículo ventral com protuberância desenvolvida; margens látero-medianas do divertículo ventral, em vista ventral, curvas e pouco acentuadas.

Biometria dos parátipos $(\mathrm{m} / \mathrm{f})$. - Comprimento total do corpo: 10,1 - 10,8 $\mathrm{mm} / 10,7-11,5 \mathrm{~mm}$; largura máxima do corpo: 4,9-5,2 mm / 5,1 - 5,3 mm; comprimento do primeiro segmento do rostro: $0,50-0,64 \mathrm{~mm} / 0,60-0,64$ $\mathrm{mm}$; comprimento do segundo segmento do rostro: 0,60 - 0,70 mm / 0,70 mm; comprimento do anteóculo: 0,64 $\mathrm{mm} /$ 0,64 mm; comprimento da porção anterior da sutura frontogenal: $0,32-0,35 \mathrm{~mm} / 0,32-0,35 \mathrm{~mm}$; comprimento da porção posterior da sutura frontogenal: $0,32-0,35 \mathrm{~mm} /$ $0,32-0,35 \mathrm{~mm}$; comprimento do interóculo: $0,70 \mathrm{~mm} / 0,70$ $\mathrm{mm}$; comprimento do pronoto em sua porção mediana: 1,85 $-1,90 \mathrm{~mm} / 1,75-1,90 \mathrm{~mm}$; largura posterior do pronoto: $3,70-3,80 \mathrm{~mm} / 3,50-3,80 \mathrm{~mm}$.

\section{ETIMOLOGIA}

Essa nova espécie foi nomeada em homenagem ao Dr. Jorge Luiz Nessimian (Laboratório de Entomologia, Departamento de Zoologia, UFRJ, Rio de Janeiro, Brasil), cuja dedicação e empenho à entomologia no intuito de formar um grupo de pesquisa para o estudo de insetos aquáticos nos inspira a cada dia.

\section{NOTAS}

Algumas características da genitália masculina são compartilhadas entre $B$. parvum e $B$. nessimiani, sp. nov. $\mathrm{O}$ aspecto geral do divertículo ventral é similar, inclusive pela condição não dilatada das margens látero-dorsais do divertículo ventral (Figuras 4B, 4E). Entretanto, o ápice do divertículo ventral, em vista dorsal, dos representantes de $B$. parvum não é truncado como observado em $B$. nessimiani, sp. nov. (Figura 4C), e a presença de conspícuas reentrâncias nele, em vista dorsal, a difere dessa nova espécie. Os braços dorsais de $B$. parvum são mais curtos e divergentes, enquanto os dos representantes da nova espécie são mais longos e abruptamente convergentes em seus ápices (Figuras 4B, 4E). Além disso, a relação largura-comprimento do divertículo ventral é menor que 1,00 em $B$. parvum e igual a 1,00 em $B$. nessimiani, sp. nov.

No que concerne ao tamanho do corpo, as medidas de seu comprimento e de sua largura estão muito próximas daquelas tomadas dos espécimes examinados de B. nicaeum (entre 11,4 e 13,7 mm de comprimento). No entanto, os representantes de B. nicaeum apresentam o divertículo ventral com suas margens látero-dorsais dilatadas (Estévez \& Polhemus, 2006).

Belostoma nessimiani, sp. nov. enquadra-se no passo 9 da chave de Nieser \& Melo (1997:60), o qual distingue $B$. micantulum de B. plebejum. Belostoma nessimiani, sp. nov. está em melhor conformidade com B. micantulum, pois ambas enquadram-se no intervalo de comprimento do corpo de 10,5 a 13,0 mm. Os representantes de B. micantulum e $B$. nessimiani, sp. nov. apresentam as margens látero-medianas do divertículo ventral curvas (Figuras 4F-G), pouco acentuadas, enquanto as dos representantes de B. plebejum, mais elípticas, com uma curva ligeiramente mais acentuada em sua porção látero-mediana. Ainda em $B$. plebejum, a porção ventroapical do divertículo ventral apresenta uma protuberância 

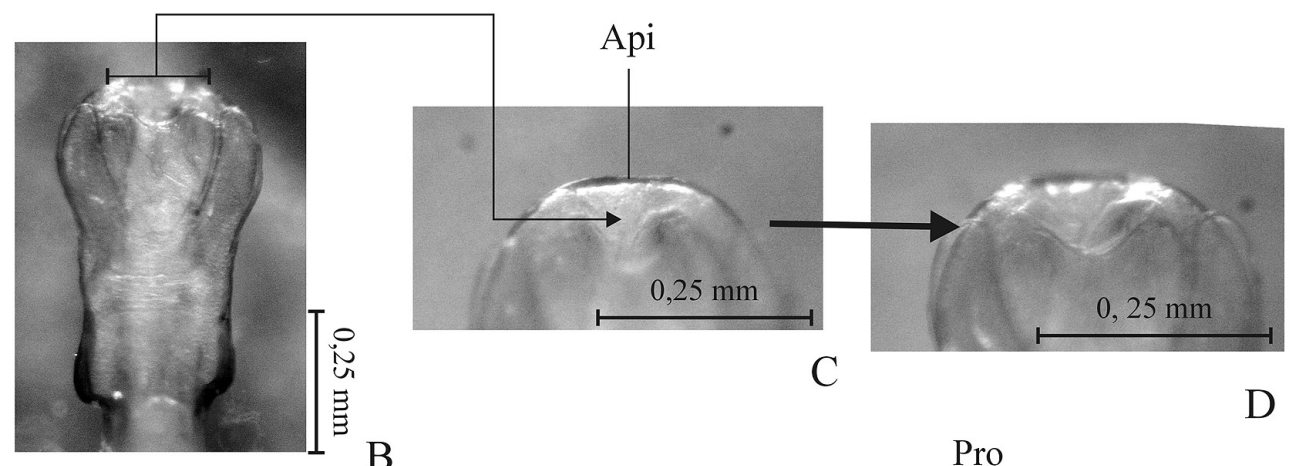

C

$\mathrm{D}$

B
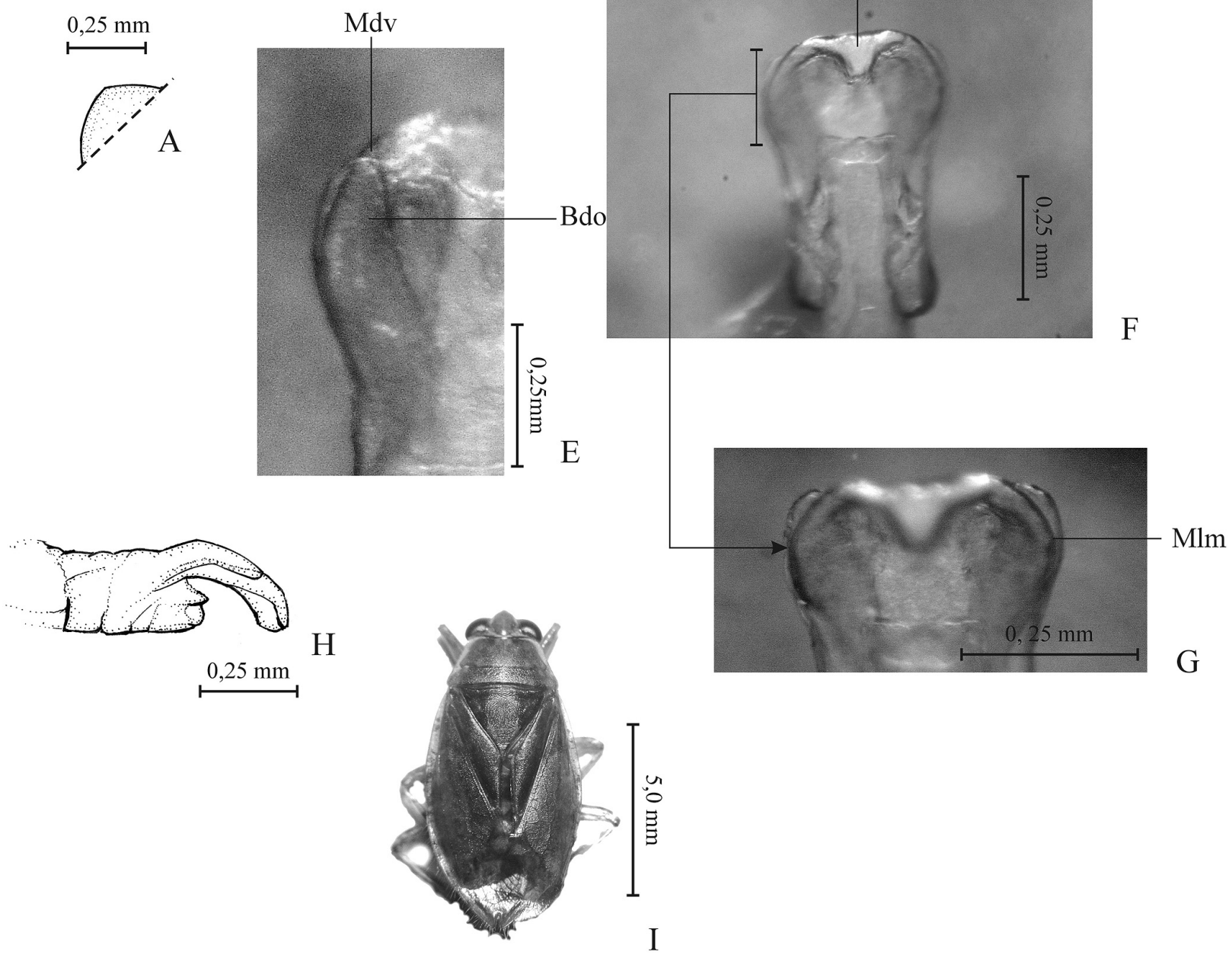

Figura 4 - Belostoma nessimiani Ribeiro \& Alecrim, sp. nov. (Belostomatidae). Holótipo (INPA): A, carena prosternal, vista lateral; B-G, falossoma: B, vista dorsal; C-D, porção posterior do falossoma, vista dorsal: $C$, detalhe do ápice do divertículo ventral; $D$, detalhe da porção dorsal próxima ao ápice do divertículo ventral; $\mathrm{E}$, detalhe do formato do braço dorsal e da margem látero-mediana do divertículo ventral mostrando seus aspectos, vista dorsal; F, vista ventral; G, porção posterior do falossoma mostrando o formato das margens látero-medianas do divertículo ventral, vista ventral; H, vista lateral; I, holótipo, vista dorsal. Api, ápice do divertículo ventral; Bdo, braços dorsais; Mdv, margem látero-dorsal; Mlm, margem látero-mediana dorsal; Pro, protuberância ventro-apical mediana. 
ligeiramente mais pronunciada (Nieser, I975:I27). Quanto às duas espécies mais similares, os representantes de $B$. micantulum apresentam as margens látero-medianas do divertículo ventral ligeiramente mais acentuadas do que as da espécie nova, os braços dorsais ligeiramente mais largos e divergentes e a região dorso-mediana do divertículo com depressão longitudinal mais desenvolvida.

Ao tentar identificar essa nova espécie a partir da chave de identificação de Estévez \& Polhemus (2007), o passo 2 não possui um conjunto de características que condiz com as condiçōes encontradas na carena prosternal dos espécimes estudados, pois apesar desta ter aspecto agudo, ela não é ligeiramente projetada para a porção anterior do corpo (Figura 4A). Entretanto, se for considerada ligeiramente projetada anteriormente, essa nova espécie enquadra-se no passo 6 da chave de Estévez \& Polhemus (2007), o qual distingue B. nicaeum de B. plebejum. Belostoma nessimiani, sp. nov. está em melhor conformidade com $B$. plebejum, se forem consideradas algumas características de sua genitália masculina, pois ambas apresentam as margens látero-dorsais do divertículo ventral não espessadas (Figura 4E). Entretanto, considerando o tamanho do corpo, essa nova espécie está em melhor conformidade com B. nicaeum, pois ambas apresentam o comprimento do corpo menor que $13,0 \mathrm{~mm}$.

CHAVE DICOTÔMICA DE IDENTIFICAÇÃO PARA AS ESPÉCIES DE Belostoma DO GRUPO plebejum sensu NIESER (ESPÉCIES NOVAS INCLUÍDAS)

A chave se baseou nas informaçōes disponíveis nos estudos de Estévez \& Polhemus (2007). Muitas espécies do grupo só podem ser distinguidas por combinaçôes de características. Além disso, a chave proposta é destinada, primariamente, para espécimes do sexo masculino e, por isso, ao se identificar fêmeas, deve se ter em mente as dificuldades encontradas na identificação dessas espécies.

1a. - Comprimento da porção anterior da sutura frontogenal igual ao da porção posterior (Sfa, Sfp, Figura 1B); machos com a região mediana e dorsal do divertículo ventral do falossoma com uma depressão profunda e comprida; ápice do divertículo afilado e deformado (com um corte profundo em forma aproximada de "V"), sem uma protuberância desenvolvida em vista ventral; margens látero-dorsais do divertículo espessadas; braços dorsais estreitos, curtos e sempre divergentes; largura do divertículo ventral do falossoma duas ou mais vezes o seu comprimento 2 ("grupo pygmeum Lauck" dos autores)

1b. - Comprimento da porção anterior da sutura frontogenal menor que o da porção posterior; região mediana e dorsal do divertículo ventral do falossoma com uma depressão pouco profunda, não muito comprida (Figura 3D), ou inexistente; ápice do divertículo arredondado, truncado ou cortado obliquamente (Figura 3F), nunca deformado, com protuberância desenvolvida em vista ventral (Figura 3F, Pro); margens látero-dorsais do divertículo não espessadas (Figuras 3E, 4E, Mdv); braços dorsais geralmente largos, longos e quase sempre convergentes em seus ápices (Figura $3 \mathrm{E}, \mathrm{Bdo})$; largura do divertículo ventral do falossoma menor que duas vezes o seu comprimento ......................

2a (1a). - Razão entre os comprimentos do primeiro e do segundo segmentos do rostro entre 0,80 e 0,87 (Figuras 1C, Cps, Css); carena prosternal voltada para a parte anterior do corpo, com sua borda anterior curva; largura do divertículo ventral maior que duas vezes o seu comprimento em vista ventral ..3

2b. - Razão entre os comprimentos do primeiro e do segundo segmentos do rostro entre 0,88 e 0,95 ; carena prosternal não voltada para a parte anterior do corpo; largura do divertículo ventral do falossoma duas vezes o seu comprimento em vista ventral

(Dufour) (Bolívia, Brasil, Paraguai, Peru) B. pygmeum

3a (2a). - Carena prosternal não proeminente; largura do divertículo ventral do falossoma maior que três vezes o seu comprimento em vista ventral; comprimento dos braços dorsais menor que o da base do falossoma. B. lariversi De Carlo (Peru)

3b. - Carena prosternal proeminente; largura do divertículo ventral do falossoma duas vezes e meia o seu comprimento; comprimento dos braços dorsais igual ao da base do falossoma ......... B. nicaeum Estévez \& Polhemus (Brasil)

$4 a$ (1b). - Razão entre os comprimentos do primeiro e do segundo segmentos do rostro entre 0,80 e 0,87 ........... 5

4b. - Razão entre os comprimentos do primeiro e do segundo

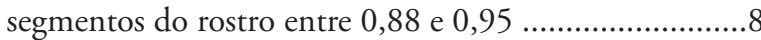

$5 \mathrm{a}(4 \mathrm{a})$. - Comprimento total do corpo a partir de 10,1 mm, muito freqüentemente maior do que $11,0 \mathrm{~mm}$; carena prosternal de aspecto arredondado, não se projetando anteriormente ...6

5b. - Comprimento total do corpo entre 9,5 e 11,1 $\mathrm{mm}$; carena prosternal de aspecto agudo, ligeiramente projetando-se anteriormente .............. B. parvum Estévez \& Polhemus (Brasil, Colômbia, Guiana, Suriname, Venezuela)

6a (5a). - Comprimento total do corpo entre 10,5 e 13,0 $\mathrm{mm}$; margens látero-dorsais do divertículo ventral com curvatura pouco acentuada, de forma pouco elíptica (Figs 4E, 4F, 4G, Mlm); porção ventro-apical do divertículo com protuberância pouco desenvolvida (Figura 4F, Pro) ......7

6b. - Comprimento total do corpo maior que $13,0 \mathrm{~mm}$; margens látero-dorsais do divertículo ventral com curvatura muito acentuada em sua porção látero-mediana, de forma muito elíptica; porção ventro-apical do divertículo com 
uma protuberância pronunciada

B. plebejum (Stål) (Argentina, Bolívia, Brasil, Peru, Uruguai)

7a (6a). - Depressão mediana e dorsal do divertículo ventral muito desenvolvida; braços dorsais divergentes B. micantulum (Stål) (Argentina, Bolívia, Brasil, Colômbia, Guiana, Paraguai, Venezuela)

7b. - Depressão mediana e dorsal pouco desenvolvida (Figura 4D); braços dorsais abruptamente convergentes (Figuras 4B, 4E)......... B. nessimiani Ribeiro \& Alecrim, sp. nov. (Brasil)

8a (4b). - Margens látero-dorsais do divertículo ventral muito marcadas e bem definidas (Figura 3E); braços dorsais do divertículo ventral ligeiramente convergentes (Figura 3B) ....... B. estevezae Ribeiro \& Alecrim, sp. nov. (Brasil)

8b. - Margens látero-dorsais do divertículo ventral pouco marcadas e não muito definidas; braços dorsais do divertículo ventral estreitos e convergentes .............. $B$. minusculum (Uhler) (Costa Rica, Honduras, Nicarágua, Panamá, Trinidad, Venezuela)

\section{AGRADECIMENTOS}

À Ana L. Estévez (Facultad de Ciencias Naturales y Museo, Museo de La Plata), à Angela M. Sanseverino (Instituto de Biologia, UFRJ), ao Márcio Felix (FIOCRUZ) e aos três revisores anônimos da revista, pela leitura crítica deste manuscrito. Aos curadores R. T. Schuh (AMNH), J. L. Nessimian (DZRJ), C. Magalhães (INPA), G. Mejdalani (MNRJ), pelo empréstimo e deposição dos espécimes usados neste estudo. Ao Conselho Nacional de Desenvolvimento Científico e Tecnológico (CNPq) e à Coordenação de Aperfeiçoamento de Pessoal de Nível Superior (CAPES), pela concessão de bolsas de doutorado e mestrado e outros benefícios aos autores.

\section{BIBLIOGRAFIA CITADA}

Arnett-Jr. R.H.; Samuelson, G.A.; Nishida, G.M. 1993. The insect and spider collections of the world. Sandhill Crane Press, Inc., $2^{\text {nd }}$ edition, Gainesville. vi + 310pp.

Bachmann, A.O. 1977. Heteroptera. In: Hurlbert, S.H.; VillalobosFigueroa, A. (Eds). Biota Acuática de Sudamérica Austral. San Diego State Univ., San Diego. p. 189-212.

Estévez, A.L. 1996. Revision sistematica del género Belostoma Latreille (Hemiptera - Heteroptera). Grupos de Belostoma (Belostoma) triangulum, B. (B.) minor, B. (B.) oxyurum, B. (B.) plebejum $y$ B. (B.) denticolle. Tese de Doutorado, Facultad de Ciencias Naturales y Museo/Universidad Nacional de La Plata, La Plata. $\mathrm{vi}+117 \mathrm{pp}$.

Estévez, A.L.; Armúa-de-Reyes, C. 2003. Una nueva especie del género Belostoma (Heteroptera: Belostomatidae). FACENA, 19: 149-153.
Estévez, A.L.; Polhemus, J.T. 2001. The small species Belostoma (Hemiptera: Belostomatidae). I. Introduction, key to species groups and a revision of the denticolle group. Iheringia, Sér. Zool., 91: 151-158.

Estévez, A.L.; Polhemus, J.T. 2007. The small species of Belostoma (Heteroptera: Belostomatidae). Revision of plebejum group. Rev. biol. trop., 55(1): 147-155.

Estévez, A.L.; Schnack, J.A.; Armúa-de-Reyes, C. 2006. The thoracic sclerites of Belostoma Latreille (Hemiptera: Belostomatidae) and their usefulness for species identification. Zootaxa, 1175: 31-35.

Gorb, S.N.; Perez-Goodwyn, P.J. 2003. Wing-locking mechanisms in aquatic Heteroptera. J. Morphol., 257: 127-146.

Hamilton, K.G.A. 1981. Morphology and evolution of the rhynchotan head (Insecta: Hemiptera, Homoptera). Can. Ent., 113(11): 953-974.

Lauck, D.R. 1962. A monograph of the genus Belostoma (Hemiptera). Bull. Chicago Acad. Sci., 11(3): 34-81.

Lauck, D.R. 1963. A monograph of the genus Belostoma (Hemiptera), part II. Bull. Chicago Acad. Sci., 11(4): 82-101.

Lauck, D.R. 1964. A monograph of the genus Belostoma (Hemiptera), part III. Bull. Chicago Acad. Sci., 11(5): 102-154.

Lauck, D.R.; Menke, A.S. 1961. The higher classification of the Belostomatidae (Hemiptera). Ann. ent. Soc. Amer., 54: 644657.

Mayr, G. 1871. Die Belostomiden. Verh. zool.- bot. Ges. Wien, 21: 399-440.

Menke, A.S.; Lauck, D.R. 1962. The Machris Brazilian Expedition-entomology: Belostomatidae (Hemiptera). Contr. Sci., 55: 3-8.

Nieser, N. 1975. The water bugs (Heteroptera: Nepomorpha) of the Guyana Region. Uitg. natuurw. Studkring Suriname, 16(81): 88-128.

Nieser, N.; Melo, A.L. 1997. Os heterópteros aquáticos de Minas Gerais. Guia introdutório com chave de identificação para as espécies de Nepomorpha e Gerromorpha. Ed. UFMG, Belo Horizonte, Minas Gerais. 180pp.

Parsons, M.C. 1964. The origin and development of the Hemipteran cranium. Can. J. Zool., 42: 409-432.

Parsons, M.C. 1974. The morphology and possible origin of the Hemipteran loral lobes. Can. J. Zool.,_52: 189-202.

Ribeiro, J.R.I. 2005. Família Belostomatidae Leach, 1815 (Insecta: Hemiptera: Heteroptera): chave e catálogo de identificação para as espécies ocorrentes no Estado do Rio de Janeiro, Brasil. Arq. Mus. Nac., 63(2): 247-262.

Ribeiro, J.R.I. 2007. A review of the species of Belostoma Latreille, 1807 (Insecta, Heteroptera, Belostomatidae) from the four southeastern Brazilian states. Zootaxa, 1477: 1-70.

Recebido em 16/11/2006

Aceito em 09/03/2007 